\title{
BMJ Open A qualitative exploration of information-seeking by electronic nicotine delivery systems (ENDS) users in New Zealand
}

\author{
Lindsay Robertson, ${ }^{1}$ Janet Hoek, ${ }^{2,3}$ Mei-Ling Blank, ${ }^{2,3}$ Rosalina Richards, ${ }^{1}$ \\ Pamela Ling, ${ }^{4}$ Lucy Popova, ${ }^{5}$ Lydia McMillan ${ }^{2,3}$
}

To cite: Robertson L, Hoek J, Blank M-L, et al. A qualitative exploration of informationseeking by electronic nicotine delivery systems (ENDS) users in New Zealand. BMJ Open 2018;8:e023375. doi:10.1136/ bmjopen-2018-023375

- Prepublication history and additional material for this paper are available online. To view these files, please visit the journal online (http://dx.doi org/10.1136/bmjopen-2018023375).

Received 4 April 2018 Revised 21 September 2018 Accepted 25 September 2018

D) Check for updates

(C) Author(s) (or their employer(s)) 2018. Re-use permitted under CC BY-NC. No commercial re-use. See rights and permissions. Published by BMJ.

${ }^{1}$ Cancer Society Social and Behavioural Research Unit, Department of Preventive and Social Medicine, University of Otago, Dunedin, New Zealand ${ }^{2}$ Department of Public Health, University of Otago, Dunedin, New Zealand

${ }^{3}$ Department of Marketing, University of Otago, Wellington, New Zealand

${ }^{4}$ Center for Tobacco Control Research and Education, University of California San Francisco, Dunedin, New Zealand

${ }^{5}$ School of Public Health, Georgia State University, Atlanta, Georgia, USA

Correspondence to Dr Lindsay Robertson; I.robertson@otago.ac.nz

\section{ABSTRACT}

Objectives Given recent increases in awareness and uptake of electronic nicotine delivery systems (ENDS), we aimed to explore ENDS users' information needs and search behaviours and whether information gaps exist. Design Qualitative study using semistructured interviews that probed participants' smoking behaviours and ENDS use; data in this study examine ENDS information-seeking behaviours. We used qualitative description to analyse interview transcripts.

Participants and setting We recruited 39 current ENDS users ( 20 dual users and 19 exclusive ENDS users who reported having previously smoked cigarettes regularly) aged 18 and over, from three urban centres in New Zealand.

Results Several participants used Google to search for information on ENDS' health effects, but described the material they retrieved as vague or contradictory. Some interpreted the absence of information on long-term health effects as evidence ENDS did not pose potential health risks, and several perceived e-liquids as benign. Many relied on information sourced from other ENDS users, gleaned from online forums, YouTube or from discussions with friends and acquaintances; these sources typically presented ENDS positively. Several participants found specialist ENDS retailers provided valuable advice; nonspecialist store staff generally lacked detailed product knowledge and sometimes offered inaccurate information. Conclusion People seeking information on ENDS' health effects are more likely to retrieve recommendations, product reviews and endorsements from online sources or through exchanges with other users, than they are to find scientific data. Health authorities could help meet potential users' information needs by, first, creating and frequently updating objective lay summaries of the latest scientific evidence; second, by mandating licensing for retailers with guidelines to disclose uncertainty over ENDS' efficacy for cessation and longer-term health effects, and the need for complete substitution of ENDS for combustible cigarettes among those who use these products.

\section{INTRODUCTION}

Awareness of electronic nicotine delivery systems (ENDS) has risen rapidly over recent years. ${ }^{1-3}$ Usage rates have also increased; data
Strengths and limitations of this study

- Our qualitative approach provided detailed data of electronic nicotine delivery systems (ENDS) users' information-seeking behaviour and their perceived information gaps.

- We recruited a diverse group of participants, comprising both exclusive ENDS users who had previously smoked tobacco, and dual users of ENDS and tobacco.

- Our qualitative approach and small sample mean our findings are not necessarily representative of the wider New Zealand ENDS user population.

from large US, EU and New Zealand (NZ) surveys suggest around $12 \%-17 \%$ of the general population have tried ENDS, ${ }^{4-6}$ with greater usage among current and former smokers. ${ }^{4-6}$

ENDS use (commonly called 'vaping') represents a new behaviour pattern and potential users may know little about how to establish and sustain practices that promote smoking cessation. Surprisingly few studies have explored potential users' information needs or how such needs are addressed. A 2013 survey of the US public found few people $(<5 \%)$ searched for information about ENDS, though current tobacco smokers were around eight times as likely as non-smokers to look for information. ${ }^{7}$ Other studies report that internet search engine queries for ENDS have increased exponentially over time..$^{8-10}$ In the UK and USA, ENDS-related queries are several hundredfold more prevalent than queries for other smoking cessation and potentially reduced-harm tobacco products. ${ }^{9}$ Information may also come from online ENDS user communities, which have evolved rapidly using platforms such as Reddit ${ }^{11-13}$ to share information, ideas and expertise. 
Although full safety profiles on ENDS use are yet to be developed, and ENDS' efficacy as a smoking cessation tool remains disputed, ${ }^{14-16}$ many countries, including NZ, allow sales of nicotine-containing e-liquid. ${ }^{17}$ This stance assumes that full transition from smoking to exclusive ENDS use will present fewer risks than continued smoking. ${ }^{18}$ However, given uncertainty over ENDS' risks and benefits, and because the dominant usage pattern is dual use rather than complete substitution, ${ }^{19} 20$ it is timely to assess potential users' information needs and how full transition from smoking to exclusive ENDS use could be more effectively supported.

A small 2008 international survey of ENDS users found that a minority ( 8 out of 81 ) felt concerned about the lack of information regarding the composition of ENDS aerosol and health risks of vaping. ${ }^{21}$ More recent work suggests potential users continue to regard information about ENDS' health effects as important, ${ }^{1}$ though this study did not examine participants' access to such data. Gaps may also exist between the sources participants regard as trustworthy and those they use. ${ }^{22}$ For example, while doctors are regarded as the most reliable source of information about ENDS' health effects, very few participants surveyed $(<7 \%)$ had actually sought ENDS information from a health professional. Instead, most turned to the internet or product packaging, or sought advice from other ENDS users. ${ }^{1}$

Discrepancies between what ENDS users or potential users seek and what they find might contribute to the confusion and misperceptions about ENDS and to continued dual use rather than complete switching to ENDS. We examined these discrepancies using a qualitative approach to describe information ENDS users seek and retrieve, where they search, what they find and whether the available information meets their needs. NZ represents a unique setting in which to address these questions as it has an ambitious endgame goal $^{23}$ and aims to reduce smoking prevalence to below $5 \%$ in all population groups by 2025. At the time of data collection, NZ law did not allow legal sale of nicotine-containing ENDS (a 2018 court case has reversed that position). ${ }^{17}$ Given that many smokers do not cease smoking combustible tobacco after 'switching' to ENDS, ${ }^{1619} 2024$ probing information gaps could identify opportunities to support transition from smoking to exclusive ENDS use among smokers using ENDS.

\section{METHODS}

\section{Sample and recruitment}

This study was part of a larger project examining ENDS use in NZ. To explore information-seeking behaviours, we recruited current ENDS users aged 18 and over who had smoked at least 100 cigarettes in their lifetime, and who were either exclusive ENDS users or dual users (ie, also smoked tobacco at least once a month). Participants were defined as current ENDS users if they used ENDS at least once a month (nearly all participants were daily users with only one reporting less than weekly use). We recruited Māori (NZ's indigenous population), Pacific and NZ European participants from three urban centres in New Zealand. Recruitment strategies included social media and community advertising (including in vape stores), and whanaungatanga (kinship) and professional networks to specifically recruit Māori and Pacific peoples. We used screening questions to determine potential participants' ENDS user status, and set approximate quotas of 20 participants in each group (exclusive ENDS use and dual use), with final numbers determined by data saturation. Participants received a NZ $\$ 40$ gift voucher to recognise any costs incurred.

\section{Data collection}

Our semistructured interview guide explored participants' ENDS information-seeking behaviour. Specifically, we asked participants what information they had sought about ENDS, where they had searched for this information, what they retrieved, how helpful each information source was, where they had found information about different devices and their perceptions about ENDS' potential harms and benefits (see online supplementary file 1 for the interview guide, which includes details of other question topics, such as participants' smoking and ENDs behaviours and perceptions). This approach retained flexibility in question wording and sequencing, ensured interviews remained conversational and permitted detailed probing. Participants completed a brief background questionnaire that collected information on their smoking and ENDS practices and demographics, and provided written informed consent before the interview commenced. Three members of the research team (LR, JH and MB) conducted the interviews between December 2016 and July 2017; these lasted approximately $70 \mathrm{~min}$ (range: 45 to $90 \mathrm{~min}$ ).

\section{Data analysis}

We recorded interviews with participants' consent and subsequently transcribed the digital recordings verbatim. We analysed the transcripts using qualitative description, a pragmatic qualitative research method that supports 'a rich, straight description' of the data. ${ }^{25}$ This widely used analytic approach comprises coding interview data, reflecting on the data, identifying recurring phrases and themes and balancing similarities and differences in participants' accounts to develop a nuanced interpretation of the full data set. ${ }^{20}$ LR coded the transcripts using a line-by-line open coding approach; she and JH met frequently to discuss the data analysis and codes, and to compare participants' accounts with particular attention to divergent views and practices. To triangulate the data, $\mathrm{LR}$ and $\mathrm{JH}$ reviewed interpretations and the themes these supported, consolidated the coding structure. We used NVivo 11 to manage the data and assigned a pseudonym to all participants. 


\section{Patient and public involvement}

Study participants were not involved in the study design or any other aspect of conducting the study. We intend to disseminate results to study participants through a written summary; academic outputs will be publicised through community networks, social media and traditional media channels.

\section{RESULTS}

\section{Participants' characteristics}

The sample comprised 16 women and 23 men aged 19 to 65 years (median age 34 years). Twenty participants were dual users who reported both smoking and vaping at least once a month, while 19 participants reported being exclusive ENDS users. Table 1 shows supplementary information for each participant: 33 participants used ENDS daily, 5 weekly and one less than weekly; most participants were relatively new ENDS users, reporting at least weekly ENDS use for between 1 month and 1 year. All but two participants owned either a second-generation or third-generation device; two participants did not own an ENDS device; none were currently using a first-generation device (eg, a disposable model or rechargeable 'ciga-like'). Nine participants identified as Māori, five as Pacific, two as Māori and Pacific, two as 'Other' (specifically, Indian and Middle Eastern) and the remaining 21 participants were NZ European. The qualitative analysis did not reveal any differences in information-seeking by ethnicity.

\section{Health-related information \\ Online information searching}

Participants typically used internet search engines (ie, Google) to locate health-related information, such as the long-term effects of vaping and the risks relative to smoking. Charlie searched whether: 'it (vaping) was carcinogenic' and Cindy had tried to find out: 'are people doing this (vaping) and ending up finding out they have lung cancer?'. The nature and depth of participants' search strategies varied, though most reported cursory rather than detailed searches. For example, Hannah had searched 'a wee bit online, but only a little bit' and Hector had 'just Googled bad things about vaping, good things about it.' Most had not searched for specific websites but instead accessed the first articles or links returned by the search engine. Few paid attention to the website source; Pete elaborated: 'You just Google it and...don't really take notice of where it came from, but you just read it.' Very few had searched further for original sources, such as research papers; Gina was one exception: '...being a scientist, I went and dug out the article and read it.'

Despite seeking reassurance, participants did generally not find the information they retrieved helpful; Kelvin represented several others' experiences:

I did try to look for stuff about how safe it is... like whether it's still sort of cancerous or whatever, that sort of thing... I don't think there was a great deal of like, good quality evidence, you know? There's not really any proper research studies.

Other participants reported only finding information on serious but seemingly infrequent negative effects of ENDS:

I did a general search on how safe is the vape and the thing that came up was the popcorn lung, that was pretty much it, and the blowing up of the vape in the mouth... (Gina)

\section{Reconciling ambiguous information}

Rather than locating robust studies, participants instead found conflicting and contradictory messages, which they struggled to interpret. Brett commented: 'I found out that, you know, vaping is $95 \%$ less harmful (than smoking). Other places said it's 70\%; other places say it's just as bad (as smoking).' Faced with inconsistent and incomplete information about ENDS' long-term health effects, participants adopted varied strategies to evaluate the information they retrieved. Some judged the credibility of online information from the 'specialised' appearance of websites; for example, Tilly believed a website 'devoted to e-cigarettes' to be a reliable information source:

It looked pretty reliable, so I just went off that... I think it was a website about e-cigarettes specifically... I wouldn't have gone onto it if I didn't see that it was this website devoted to e-cigarettes.

A small minority reported assessing information critically by investigating the website source: 'to see how reputable their information was' (David), or by considering any potential bias, such as 'who is funding it and where it is coming from' (Gina). Yet even these attempts to appraise information did not produce robust conclusions, as Charlie described:

I went through... tried to weigh both sides and make a decision... I got to the conclusion at the end. Whether or not it's true, I don't know.

Participants had difficulty recalling the exact sites they visited, but used the balance of information they located to infer ENDS were not harmful. In the absence of information about ENDS' long-term effects, many assumed ENDS were harmless, at least compared with the known and well-documented risks of smoking. Ewan elaborated: 'I think if you're smoking you're almost guaranteed to die from it, whereas so far no one's died from vaping' and concluded vaping was probably harmless after consulting 'ten to fifteen webpages... that all said the same thing: there's nothing in the exhaled vapour except a cloud of steam.'

By juxtaposing the 'well-established' toxicity of tobacco and the lack of information about ENDS, participants extrapolated the latter to interpret ENDS as benign. Kelvin explained: 
Table 1 Participant characteristics

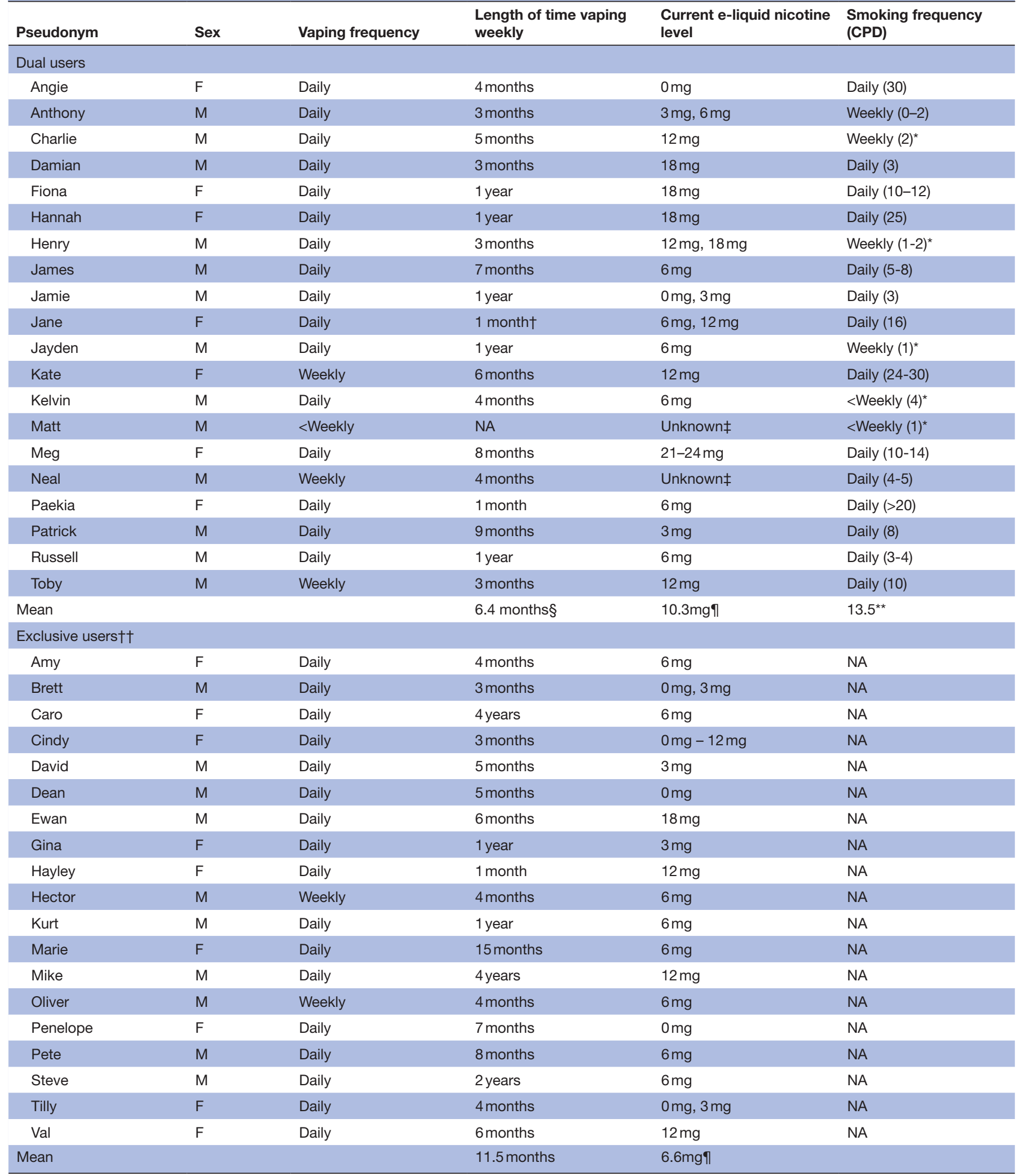

*Number in brackets represents cigarettes per day on smoking days for non-daily smokers.

†Had been using intermittently for 1 year.

¥Participants did not know nicotine content as they used others' ENDS devices.

§Among at least weekly electronic nicotine delivery systems users.

ๆUsing highest milligram given.

${ }^{*}$ Among daily smokers, using highest milligram given.

††All exclusive end users were former cigarette smokers.

CPD, cigarettes per day; NA, not applicable. 
There's like a well-defined, well-established potential harm from cigarettes, whereas with e-cigarettes, it's not well-understood what happens... a person would be like, 'it's fine until proven otherwise.'

\section{Reliance on word-of-mouth}

The lack of authoritative information on ENDS' health effects meant participants relied heavily on word-ofmouth (or word-of-mouse). Several reported seeking information from vaping-related Facebook groups, Reddit or other online forums, and found these helpful and welcoming:

I found e-cigarette-forum.com, where it had a beginners' forum so I introduced myself and asked a few questions and the replies I got were pretty friendly. Which also got me looking at more into the community aspect of it, finding more sites, more forums for me to be able to expand my information on it. (David)

Several participants noted that they had not tried to find information about ENDS online; most reported seeking ENDS-related information from friends, family members or co-workers, and some preferred these sources to online sites. Neal explained he would 'definitely ask people' over searching for information on the internet, while Meg reported having 'lengthy discussions with other people' before using ENDS. These participants felt curious about others' experiences since switching to ENDS and in-person discussions reassured them that ENDS improved users' health:

I did ask people too that I knew... and they seem fine with them. They said 'no' they hadn't been sick since they'd been on them and... they're not coughing in the mornings. (Jane)

Regardless of whether they received reassurance via an online forum or through friends or family, participants trusted the first-hand experiences of others over the conflicting information they found. Personal experience seemed more authentic and reliable, as Hector explained:

You know, you can read something that says, 'Vapes do this. Vapes do this.' But what does that person really know? Having someone who's done it and currently doing it helps, I feel like... More experienced with it. (Hector)

Participants saw information from friends who used ENDS as genuine and trustworthy: 'I didn't think Google would give me very good information about how people felt. Because these (friends) are people I trust, I would go from their opinion.' (Tilly)

\section{Perceptions and information gaps}

Participants drew several inferences from the information they amassed. Most did not associate harm with nicotine or with other e-liquid contents, and believed e-liquids to be free of cancer-causing ingredients: 'That was another pull factor for me, is that there was no known carcinogens in e-liquid' (Tilly). They regarded e-liquids as benign substances that could not plausibly cause harm:

...it's steam, you know. It's not going to harm, it's harmless (Patrick)

...it's just water... So I don't know how it could be any harmful when it's just actual water. (Amy)

Similarly, Cindy's description of e-liquid contents as 'natural' and chemical-free echoed other participants' descriptions of vaping as a pure and clean experience:

They're natural... there's like vegetable oil, and then there's like whatever to make their flavours. And something else. There's no actual full-on chemicals or anything like that. (Cindy)

Yet while participants perceived vaping as healthier than smoking, several felt uncertain about ENDS' absolute health risks, and queried whether vaping might result in lung damage due to inhaling moisture:

I'd just like to know what exactly I am inhaling into my lungs and what it's doing to me and it's probably the moisture that concerns me the most... fluid on my lungs, you know, is it doing more damage? (Angie)

As noted above, some participants wanted to know whether ENDS could cause cancer or other diseases, but found it difficult to locate specific answers:

I would like to know... can these cause lung cancer? Can they cause throat cancer? Can they cause any cancer, basically. Is it addictive?... Um, can it cause other medical problems? (Kate)

As well as health-related questions, participants sought practical advice, such as how they should calibrate the nicotine in e-liquid with their current cigarette consumption:

I'd want to know how it compares. Like, how one puff of a vape compares to the nicotine intake compared with a cigarette. (Neal)

Overall, despite searching for different details, participants found it difficult to locate information and so satisficed by relying on the 'weight' of information or privileging advice given by friends and family.

\section{Purchasing-directed information}

While many participants had health queries, others wanted pragmatic information, such as where to buy ENDS, and how to use and maintain devices. Unlike cigarettes, ENDS required new knowledge and quite different decisions. Toby had spent time 'reading reviews for (his ENDS), just to make sure it was decent and wouldn't break', while Marie wanted to know '...how to look after the equipment, how to fill it, and how to keep it charged.'

Some, like Hector, had compared the cost-effectiveness of different models: 'what's the difference between these bigger ones and these smaller ones... really just 'what's a 
good, cheap vape?". Several had investigated the potential savings of ENDS use relative to smoking; Patrick wanted to know: 'how much it was... so I can do a comparison as to buying a packet of smokes and how long that's going to last me'.

Participants used YouTube to find information, such as product review videos, which they found useful when they were beginning to use ENDS. Russell explained:

...watching the videos and stuff, they gave you complete breakdowns of how it worked and how to disassemble it and how to put it all back together and just basically how the whole thing worked.

Most saw YouTube product reviews as consumer-driven, rather than advertising, and considered information created by 'just other sorts of young guys' like themselves as credible (Russell). Some recognised overtly commercial overtones, such as 'discount codes... you can go to certain websites and get $10 \%$ off', yet nonetheless saw the videos as authentic and created by 'just sort of random people, they didn't represent any companies' (Mike).

Participants also found ENDS retailers provided helpful information on device selection, operation and maintenance:

I asked him, 'Is this durable? Is this gonna last me a while or... is it going to be faulty after a few weeks or so?' I also asked him how to clean it. And how to turn it on... and how to refill the juice. (Damian)

Many had also asked retailers about the nicotine level they should be using, and how e-liquids compared with cigarettes:

I just kind of made sure that, you know, asking her about the quantity of the nicotine that was in them and what the equivalent of the nicotine was to an actual cigarette. (Fiona)

Yet while specialist ENDS retailers offered helpful practical advice, non-specialist retailers often did not. Henry claimed staff at his local convenience store: 'didn't have a clue, they'd only just got them in. You could tell he didn't know anything about them really, he was just looking for something else to sell'. Meg recalled: 'the young woman in the shop didn't tell me there were two strengths and I found out from my friend. She said 'oh, you know, you should be on the stronger brand." Steve elaborated on the lack of helpful advice he had received:

...the problem was they only give you so much information about it and they don't explain how these help us, how to use it properly. Like how often do I need to change the coils, that's literally the most important one. 'Cause you have no idea of anything about it. They just give it to you and they just let you walk away with it... if the coil is burnt, it tastes like crap and you won't be smoking it... And it's not actually helping you.
Brett described a similar experience and, like Steve, reflected on how inadequate advice had nearly led him to conclude that vaping was not for him:

...there's a lot of those stores out there, but they don't have knowledge... they have no idea. I actually walked out of there thinking that this is not going to be for me.

Participants had diverse experiences with retailers; those who lacked specialist knowledge inadvertently deterred them from initiating ENDS use and undermined their quit attempts.

\section{DISCUSSION}

Although several participants reported searching online to determine the health effects of vaping, few found clear, consistent information. Nonetheless, participants relied heavily on word-of-mouth (including word-of-mouse) reports and several construed the lack of information as evidence of ENDS' health benefits. By contrast, they found product-usage details, such as information they found in YouTube videos and received from specialist ENDS retailers, helpful, and several drew on this information to select, set up and maintain their device.

Our findings are consistent with earlier work that found ENDS users who seek information about vaping often rely on internet search engines, followed by Facebook, online news articles and YouTube. ${ }^{7}$ Yet, while platforms such as YouTube instruct viewers on device use, ${ }^{26}$ many videos have commercial motives, use 'affiliate marketing' to promote ENDS and consistently depict ENDS in a positive light. ${ }^{27-29}$ At least some of the information participants saw as authentic and trustworthy may in fact have been constructed to promote product sales.

Information-sharing occurred through online forums, which hosted discussions on several topics, including vaping techniques, equipment, e-liquid mixing, flavours and, to a lesser extent, health effects and symptoms. ${ }^{11-13} 30$ As with YouTube, ENDS-related information on other social media platforms typically outlined benefits of ENDS use and reflected supply chain promotions ${ }^{31} 32$ as well as posts by actual ENDS users. ${ }^{13} 3031$ Although some have suggested social media discussions of ENDS use occur in an 'echo chamber', where network members amplify other members' beliefs, ${ }^{30}$ participants see these communities as offering dispassionate, authentic and reliable advice.

Our findings confirm the powerful effect word-ofmouth endorsements have on perceptions and uptake of ENDS. ${ }^{733}$ People who have more frequent conversations about ENDS with friends and family members tend to hold positive views of ENDS $^{33}$ and perceive ENDS aerosol as less harmful. ${ }^{34}$ More generally, our findings further illustrate how anecdotal experiences shape perceptions of ENDS, particularly in the absence of official information that serves as a counterpoint. 
US studies have questioned whether ENDS retail staff, including specialist vape shop staff, have the expertise or objectivity to offer reliable ENDS advice. ${ }^{35-37}$ Our participants reported positive interactions with specialist vape shop retailers, whose practical guidance assisted vaping uptake. However, positive interactions do not necessarily mean the retailers provided evidence-based cessation counselling, or that the information provided promoted public health goals. While vape store staff have expertise in device attributes and performance, successful transition from smoking to exclusive ENDS use may require additional support, such as ongoing behavioural counselling. It is unclear whether specialist retailers are equipped to provide advice on contingency management or other behavioural changes (eg, smokefree homes) that support cessation attempts, or how they would manage providing advice that could conflict with their commercial goals. ${ }^{38}$

Overall, participants sought both health-related information and usage guidance, yet had difficulty retrieving clear responses to their questions. They did not know whether the sites their search engine ranked highly were objective or commercial, and several unthinkingly assumed the former. While some had helpful interactions with ENDS retailers, others did not, and the misinformation they had received almost deterred some from making a quit attempt.

\section{Implications}

While evidence of ENDS' long-term effects may take several years to emerge, prospective users need access to the most up-to-date information available, even if this is incomplete. Health authorities have a pivotal role to play in providing resources that offer pragmatic information, such as how prospective vapers should calibrate their cigarette consumption with e-liquid nicotine levels. They could also provide health information designed for the lay public, undertake rapid evidence reviews, regularly update official websites and provide more frequent sector updates. Future work could explore the optimal format and media for this information. Optimising official sites using tags and strategies to ensure high rankings in Google searches would help drive traffic to more scientific information sources. Similarly, integrating an official evidence repository with other platforms, such as national and community cessation services, could further broaden reach and increase the proportion of potential ENDS users able to access higher quality information.

Although such a site could assist prospective ENDS users searching for online information, many may continue to seek advice at the point-of-sale. Given our participants' varied experiences, and that, as of 2018, NZ retailers are not required to have a license to sell ENDS, mandating retail licensing for all ENDS sellers could enable dissemination of up-to-date and objective information that incorporates best practices from smoking cessation if standards were established, such as requiring retailers to demonstrate knowledge of smoking cessation strategies, and mandating provision of information disclosing the risks of ENDS and the risks of dual use. Licensing standards could require retailers to apprise potential users of specific points, such as safety information or the lack of evidence supporting ENDS efficacy for smoking cessation, and ensure all point-of-sale materials contained links to official websites and behavioural counselling services.

\section{Limitations and future research}

As with all qualitative research, we have a small and non-representative sample; thus, our results need replication using a large population-based sample before they can be generalised. Future research could include experimental studies testing optimal information format, and explore information networks to assess what drives traffic to official sites. Studies are needed to identify how public health organisations can effectively communicate ENDS' potential risks and benefits, and use evidence-based counselling strategies to discourage dual use. In addition to improving potential users' knowledge and developing more robust information resources, further work is required to examine other factors that influence smoking and ENDS use behaviours. ${ }^{24}$ Furthermore, evidence that dual use is prevalent suggests transition from smoking may require more powerful stimuli and reinforcers than improved information quality and accessibility. Nonetheless, while full transition to exclusive ENDS use remains an elusive outcome for many smokers, correcting misperceptions about ENDS use and informing appropriate substitution could remove important barriers that foster dual use or relapse to smoking.

\section{CONCLUSIONS}

Our study provides further evidence that people seeking information on ENDS' health effects struggle to locate relevant information; most report locating conflicting details that leave them unsure about ENDS' risks or benefits. In countries such as NZ, where access to ENDS was recently liberalised, this confusion is particularly problematic and may increase as more non-specialist stores sell ENDS. Mandating ENDS retail licensing with minimum knowledge standards for retailers might help prospective ENDS users receive appropriate cessation advice and information that promotes complete smoking cessation. If complemented with a regularly updated official information source, this approach could reduce confusion and frustration among ENDS users, and may reduce dual use of ENDS and cigarettes.

Acknowledgements We thank the research participants who provided the data reported on in this manuscript. We also thank Anna Latu and Kale Fruean who assisted with data collection, and Stephanie Erick and Zoe Hawke who assisted with participant recruitment.

Contributors $\mathrm{JH}$ conceptualised and designed the project, and obtained research funding; PL and LP provided feedback on the funding application. With LR, MB and RR, JH designed the research protocol; PL and LP provided feedback on the protocol. LR, JH, LM and MB conducted the fieldwork; LR led analysis of the transcripts and she and $\mathrm{JH}$ developed the manuscript. MB, RR, PL and LP provided feedback on draft versions of the manuscript. JH and $L R$ responded to 
the reviewers' comments. All authors have seen and approved the final version; LR and $\mathrm{JH}$ are guarantors of the manuscript. LR is lead author and $\mathrm{JH}$ is senior author; other authors are listed in order of contribution.

Funding This work was supported by New Zealand Health Research Council grant number (16/149).

Competing interests None declared.

Patient consent Not required.

Ethics approval University of Otago Human Ethics Committee (reference16/132).

Provenance and peer review Not commissioned; externally peer reviewed.

Data sharing statement We have uploaded the semistructured interview guide as a Supplementary File. We do not intend to share the participants' interview transcripts in a repository, since some of the interview material could enable participants to be identified. However, requests for data sharing may be directed to the Corresponding Author.

Open access This is an open access article distributed in accordance with the Creative Commons Attribution Non Commercial (CC BY-NC 4.0) license, which permits others to distribute, remix, adapt, build upon this work non-commercially, and license their derivative works on different terms, provided the original work is properly cited, appropriate credit is given, any changes made indicated, and the use is non-commercial. See: http://creativecommons.org/licenses/by-nc/4.0/.

\section{REFERENCES}

1. Wackowski OA, Bover Manderski MT, Delnevo CD. Smokers sources of e-cigarette awareness and risk information. Prev Med Rep 2015;2:906-10.

2. Pepper JK, Emery SL, Ribisl KM, et al. How U.S. adults find out about electronic cigarettes: implications for public health messages. Nicotine Tob Res 2014;16:1140-4.

3. Zhu SH, Gamst A, Lee M, et al. The use and perception of electronic cigarettes and snus among the U.S. population. PLoS One 2013;8:e79332.

4. Schoenborn CA, Gindi RM. Electronic cigarette use among adults: United States, 2014: US Department of Health and Human Services, Centers for Disease Control and Prevention, National Center for Health Statistics, 2015.

5. Farsalinos KE, Poulas K, Voudris V, et al. Electronic cigarette use in the European Union: analysis of a representative sample of 27460 Europeans from 28 countries. Addiction 2016;111:2032-40.

6. New Zealand Health Promotion Agency (HPA). Data release: preliminary analysis on 2016 Health and Lifestyle Survey electronic cigarette questions. http://www.hpa.org.nz/sites/default/files/2016\% 20HLS\%20E-cig\%20preliminary\%20analysis\%20for\%20MoH_0.pdf (Accessed 1 Mar 2018).

7. Emery SL, Vera L, Huang J, et al. Wanna know about vaping? Patterns of message exposure, seeking and sharing information about e-cigarettes across media platforms. Tob Control 2014;23(Suppl 3):iii17-25.

8. Thavarajah R, Mohandoss AA, Ranganathan K, et al. Influence of legislations and news on Indian internet search query patterns of e-cigarettes. J Oral Maxillofac Pathol 2017;21:194-202.

9. Ayers JW, RibisI KM, Brownstein JS. Tracking the rise in popularity of electronic nicotine delivery systems (electronic cigarettes) using search query surveillance. Am J Prev Med 2011;40:448-53.

10. Ayers JW, Althouse BM, Allem JP, et al. Revisiting the rise of electronic nicotine delivery systems using search query surveillance. Am J Prev Med 2016;50:e173-81.

11. Wang L, Zhan Y, Li Q, et al. An examination of electronic cigarette content on social media: analysis of E-Cigarette flavor content on reddit. Int J Environ Res Public Health 2015;12:14916-35.

12. Chen AT, Zhu SH, Conway M. What online communities can tell us about electronic cigarettes and hookah use: a study using text mining and visualization techniques. J Med Internet Res 2015;17:e220.

13. Zhan Y, Liu R, Li Q, et al. Identifying topics for e-cigarette usergenerated contents: a case study from multiple social media platforms. J Med Internet Res 2017;19:e24.

14. Beard E, Brown J, Michie S, et al. Is prevalence of e-cigarette and nicotine replacement therapy use among smokers associated with average cigarette consumption in England? A time-series analysis. BMJ Open 2018;8:e016046.

15. Weaver SR, Huang J, Pechacek TF, et al. Are electronic nicotine delivery systems helping cigarette smokers quit? Evidence from a prospective cohort study of U.S. adult smokers, 2015-2016. PLoS One 2018;13:e0198047.

16. Kalkhoran S, Glantz SA. E-cigarettes and smoking cessation in realworld and clinical settings: a systematic review and meta-analysis. Lancet Respir Med 2016;4:116-28.

17. Ministry of Health. Vaping, smokeless, including heated tobacco. http://www.health.govt.nz/our-work/preventative-health-wellness/ tobacco-control/e-cigarettes (Accessed 17 Jul 2018).

18. McNeill A, Brose LS, Calder R, et al. E-cigarettes: an evidence update. https://assets.publishing.service.gov.uk/government/ uploads/system/uploads/attachment data/file/457102/Ecigarettes an_evidence_update_A_report_commissioned_by_Public_Health_ England_FINAL.pdf (Accessed 17 Jul 2018).

19. National Academies of Science Engineering and Medicine. Public health consequences of E-cigarettes. Washington, DC: The National Academies Press, 2018.

20. West R, Beard E, Brown J. Trends in electronic cigarette use in england: smoking toolkit study. http://www.smokinginengland.info/ latest-statistics/ (Accessed 15 Jul 2018).

21. Etter JF. Electronic cigarettes: a survey of users. BMC Public Health 2010;10:231.

22. Weaver SR, Jazwa A, Popova L, et al. Worldviews and trust of sources for health information on electronic nicotine delivery systems: Effects on risk perceptions and use. SSM Popul Health 2017;3:787-94

23. New Zealand Government. Government response to the report of the Māori Affairs Committee on its Inquiry into the tobacco industry in Aotearoa and the consequences of tobacco use for Mãori. http:// www.parliament.nz/en-NZ/PB/Presented/Papers/d/9/b/49DBHOH_ PAP21175 1-Government-Final-Response-to-Report-of-the-M-ori. htm (Accessed 1 Mar 2018).

24. Robertson L, Hoek J, Blank ML, et al. Dual use of electronic nicotine delivery systems (ENDS) and smoked tobacco: a qualitative analysis. Tob Control 2018:doi: 10.1136/tobaccocontrol-2017-054070 (Epub ahead of print 1 Feb 2018).

25. Neergaard MA, Olesen F, Andersen RS, et al. Qualitative description - the poor cousin of health research? BMC Med Res Methodol 2009;9:52.

26. Huang J, Kornfield R, Emery SL. 100 million views of electronic cigarette youtube videos and counting: quantification, content evaluation, and engagement levels of videos. J Med Internet Res 2016;18:e67.

27. Romito LM, Hurwich RA, Eckert GJ. A snapshot of the depiction of electronic cigarettes in youtube videos. Am J Health Behav 2015;39:823-31.

28. Luo C, Zheng X, Zeng DD, et al. Portrayal of electronic cigarettes on YouTube. BMC Public Health 2014;14:1028.

29. Yamin CK, Bitton A, Bates DW. E-cigarettes: a rapidly growing Internet phenomenon. Ann Intern Med 2010;153:607-9.

30. Allem JP, Ferrara E, Uppu SP, et al. E-cigarette surveillance with social media data: social bots, emerging topics, and trends. JMIR Public Health Surveill 2017;3:e98.

31. Dai $\mathrm{H}, \mathrm{Hao}$ J. Mining social media data for opinion polarities about electronic cigarettes. Tob Control 2017;26:175-80.

32. Laestadius LI, Wahl MM, Cho YI. \#Vapelife: an exploratory study of electronic cigarette use and promotion on instagram. Subst Use Misuse 2016:51:1669-73.

33. Hall MG, Pepper JK, Morgan JC, et al. Social interactions as a source of information about e-cigarettes: A study of U.S. adult smokers. Int J Env Res He 2016;13.

34. Tan AS, Bigman CA, Mello S, et al. Is exposure to e-cigarette communication associated with perceived harms of e-cigarette secondhand vapour? Results from a national survey of US adults. BMJ Open 2015;5:e007134.

35. Basch $\mathrm{CH}$, Kecojevic A, Menafro A. Provision of information regarding electronic cigarettes from shop employees in New York City. Public Health 2016;136:175-7.

36. Cheney MK, Gowin M, Wann TF. Vapor store owner beliefs and messages to customers. Nicotine Tob Res 2016;18:694-9.

37. Yang JS, Wood MM, Peirce K. In-person retail marketing claims in tobacco and E-cigarette shops in Southern California. Tob Induc Dis $2017 ; 15$.

38. Burbank AD, Thrul J, Ling PM. A pilot study of retail 'vape shops' in the San Francisco Bay Area. Tob Prev Cessat 2016;2. 